\title{
Observisto
}

ISSN n² 2447-4266

Vol. 5, n. 1, Janeiro. 2019

DOI: http://dx.doi.org/10.20873/uft.2447-4266.2019v5n1p455

\section{SOFTWARES LIVRES E \\ EQUIPAMENTOS \\ MANUFATURADOS: \\ possíveis recursos para a \\ integração curricular das \\ TDIC}

\author{
FREE SOFTWARES AND \\ MANUFACTURED EQUIPMENT: \\ possible resources for the curricular \\ integration of DICT
}

SOFTWARES LIBRES Y EQUIPOS MANUFACTURADOS: posibles recursos

para la integración curricular de las

TDIC

\author{
Lina Maria Gonçalves ${ }^{1}$ \\ Augustus Caeser Frank Portella ${ }^{2}$ \\ Mateus dos Santos Limeira Luz ${ }^{3,4}$
}

\section{RESUMO}

Este artigo relata uma experiência de formação de professores, com ênfase no pensamento computacional, via produção de videoaulas. Foi criado um estúdio

\footnotetext{
${ }^{1}$ Doutora em Educação: currículo (CED) pela Pontifícia Universidade Católica de São Paulo (2015). Mestre em Tecnologias da Inteligência e Design Digital (TIDD), também pela Pontifícia Universidade Católica de São Paulo (2008). Graduada em Pedagogia pelo Instituto Católico de Minas Gerais (1995). Atualmente é Professora Colaboradora no Mestrado Profissional em Gestão de Políticas Públicas (GESPOL-UFT). E-mail: lina.mg@uft.edu.br.

2 Graduação em Estatística pela Universidade Federal do Paraná, mestrado em Processos Biotecnológicos pela Universidade Federal do Paraná e Doutorado pela Rede de Biodiversidade e Biotecnologia da Amazônia Legal -BIONORTE. Atualmente sou Professor Adjunto da Fundação Universidade Federal do Tocantins-UFT e pertenço ao quadro de professores convidado dos cursos de Pós-graduação, Mestrado em Biotecnologia e Mestrado em Floresta e Meio Ambiente. E-mail: portella@uft.edu.br.

${ }^{3}$ Graduando em Química Ambiental na Universidade Federal do Tocantins (UFT), campus de Gurupi. Estagiário do Curso de Química na modalidade a distância. Desenvolvedor do estúdio alternativo de multimídia utilizando os recursos tecnológicos do Laboratório Interdisciplinar de Formação de Educadores - LIFE Gurupi. E-mail: mateus.s.l.luz@uft.edu.br.

${ }^{4}$ Endereço de contato com autores (por correio): Universidade Federal do Tocantins, Campus de Gurupi. Chácara 69-72 - Rua Badejos, Lote 7, s/n - Jardim Cervilha, Gurupi - TO, 77404-970.
} 


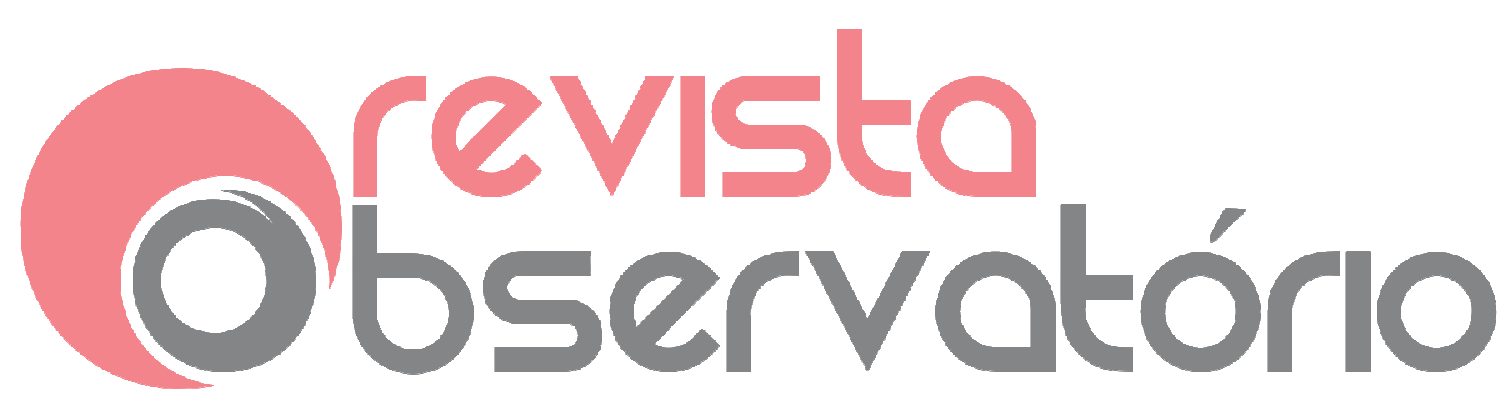

ISSN n² 2447-4266

Vol. 5, n. 1, Janeiro. 2019

DOI: http://dx.doi.org/10.20873/uft.2447-4266.2019v5n1p455

de multimídia utilizando os recursos tecnológicos do LIFE (computador, projetor multimídia, TV e lousa digital) e mecanismos manufaturados de materiais alternativos. Também foram priorizados os softwares e plataformas livres, descritos neste artigo. As videoaulas produzidas pela turma piloto mostraram que a integração curricular das mídias digitais, apesar de carecer de políticas públicas comprometidas com um processo de médio e longo prazo, pode ser potencializada via recursos existentes nas instituições educacionais e pela criação de redes de compartilhamento dos produtos e práticas desenvolvidas.

PALAVRAS-CHAVE: tecnologias digitais; pensamento computacional; videoaulas, formação de professores; materiais alternativos.

\section{ABSTRACT}

This article reports an experience of teacher training, with an emphasis on computational thinking, through videotape production. A multimedia studio was created using the technological resources of LIFE (computer, multimedia projector, TV and digital slate) and manufactured mechanisms of alternative materials. We also prioritized the softwares and free platforms, described in this article. The videotapes produced by the pilot group have shown that the curriculum integration of digital media, despite lacking public policies committed to a medium and long term process, can be enhanced through existing resources in educational institutions and through the creation of networks of sharing of products and practices.

KEYWORDS: digital technologies; computational thinking; videotapes, teacher training; alternative materials.

\section{RESUMEN}

Este artículo relata una experiencia de formación de profesores, con énfasis en el pensamiento computacional, vía producción de videojuegos. Se creó un estudio multimedia utilizando los recursos tecnológicos de LIFE (ordenador, proyector multimedia, TV y pizarra digital) y mecanismos manufacturados de 


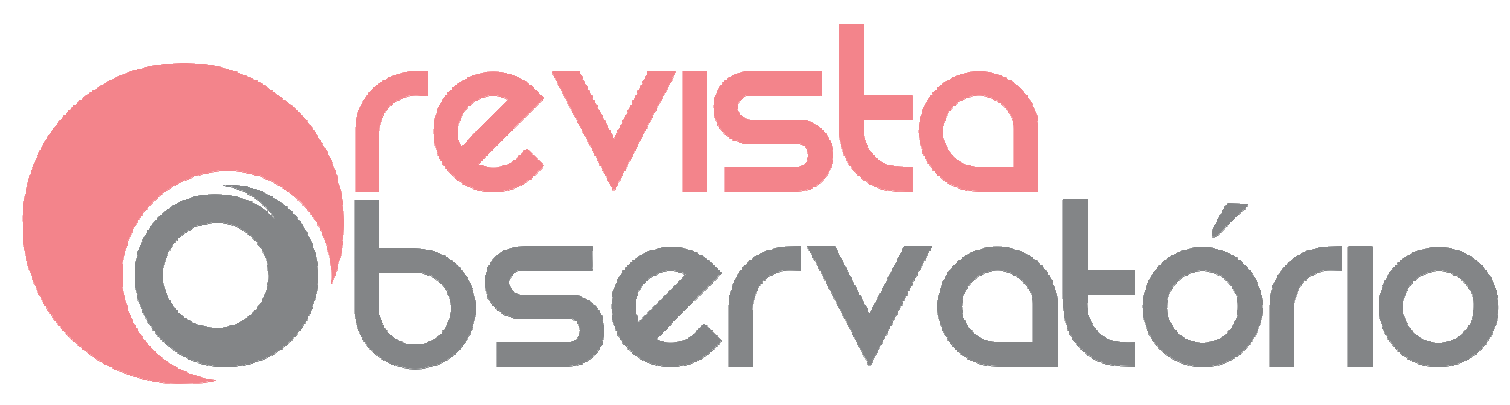

ISSN n² 2447-4266

Vol. 5, n. 1, Janeiro. 2019

DOI: http://dx.doi.org/10.20873/uft.2447-4266.2019v5n1p455

materiales alternativos. También se han priorizado los softwares y plataformas libres, descritos en este artículo. Las videocas producidas por la clase piloto mostraron que la integración curricular de los medios digitales, a pesar de carecer de políticas públicas comprometidas con un proceso de mediano y largo plazo, puede ser potencializada a través de recursos existentes en las instituciones educativas y por la creación de redes de distribución de los productos y prácticas desarrolladas.

PALABRAS CLAVE: Tecnologías digitales; Pensamiento computacional; videoconferencia, formación de profesores; materiales alternativos.

Recebido em: 30.09.2018. Aceito em: 15.11.2018. Publicado em: 14.01.2019. 


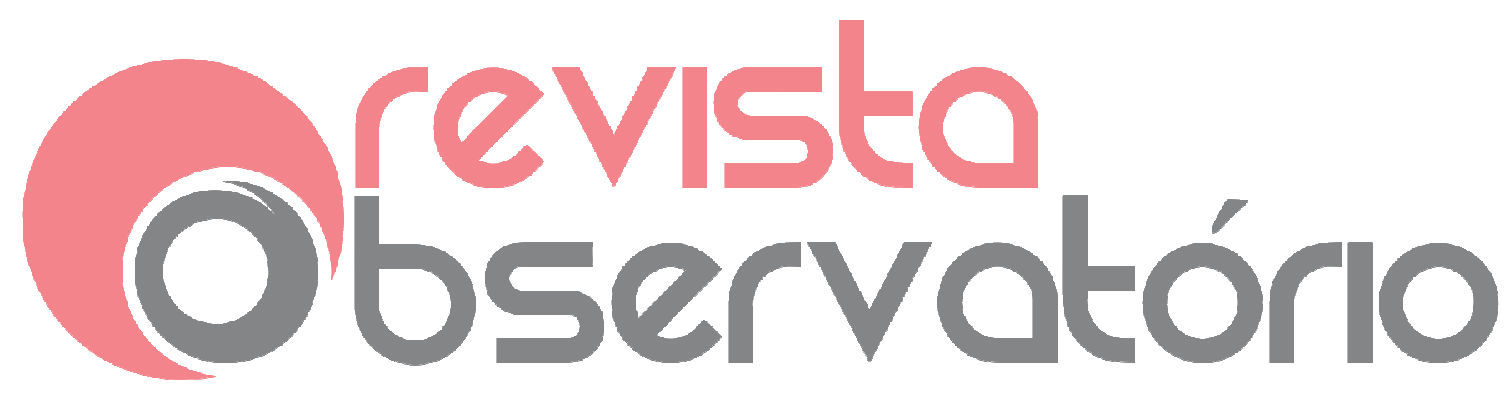

ISSN n² 2447-4266

Vol. 5, n. 1, Janeiro. 2019

DOI: http://dx.doi.org/10.20873/uft.2447-4266.2019v5n1p455

O pensamento computacional refere-se aos "processos cognitivos relacionados à abstração e decomposição para permitir a resolução de problemas utilizando recursos computacionais e estratégias algorítmicas, dentre outras habilidades" (BARCELOS et al, 2015).

\section{Introdução}

As Tecnologias da Informação e Comunicação (TIC), Tecnologias Digitais da Informação e Comunicação (TDIC) ou, simplesmente Mídias Digitais (MD), estão presentes na sociedade contemporânea. Não apenas presentes, mas tão intensamente presentes a ponto de vários estudiosos do tema se ocuparem da caracterização de tal sociedade e nomeá-la como sociedade da informação e do conhecimento (UNESCO, 2005), sociedade em rede (CASTELLS, 1999) sociedade onlife (FLORIDI, 2015) e sua cultura ser designada digital (BUCKINGHAM, 2010).

Nesta sociedade, as TDIC podem ser consideradas "instrumentos culturais de representação do pensamento humano e de atribuição de significados pelas pessoas que interagem e desenvolvem suas produções por meio delas" (ALMEIDA, 2014, p. 25). Sua presença, que invade cada minuto do nosso dia a dia, tem impactado profundamente as relações entre as pessoas e, também, o modo de interpretação do mundo e de intervenção na realidade, portanto, exercem influência na educação visto que são "estruturantes dos modos de expressar o pensamento e do currículo que se desenvolve midiatizado por elas". (ibdem)

Nas diferentes organizações, especialmente nas do sistema financeiro, como os bancos, da hora que fecham as portas para os clientes até a reabertura 


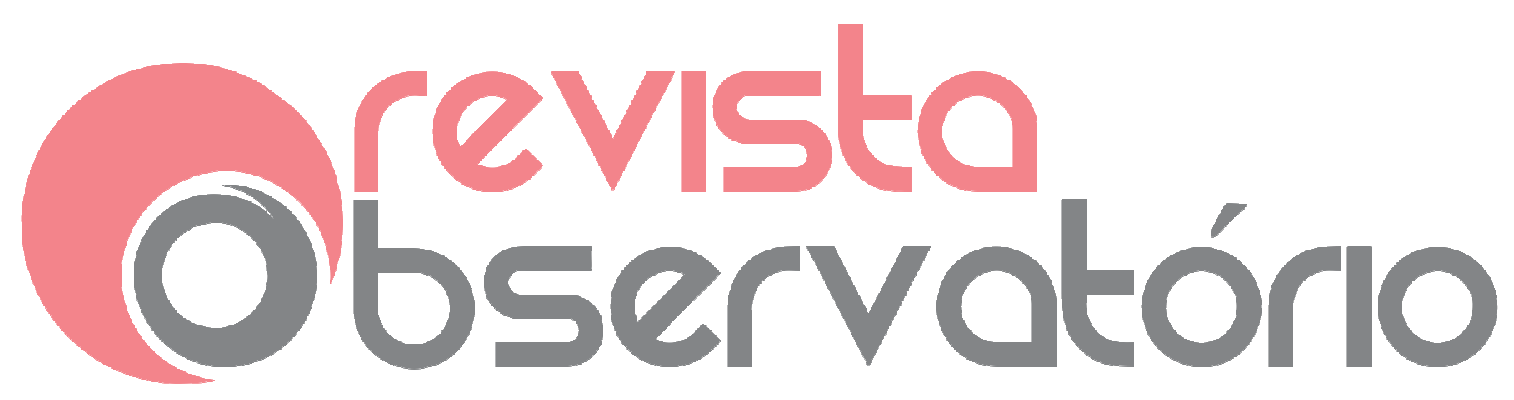

ISSN n² 2447-4266

Vol. 5, n. 1, Janeiro. 2019

DOI: http://dx.doi.org/10.20873/uft.2447-4266.2019v5n1p455

no dia posterior, ocorrem grandes mudanças. Programas informáticos são implantados, os computadores passam a ser acessados por meio de aplicativos no celular, são criadas redes de comunicação com os clientes via ferramentas tais como "fale com seu gerente", dentre outras praticidades oferecidas pelos recursos das tecnologias digitais.

Entretanto, nas escolas, em geral parece haver um descompasso em relação à velocidade das mudanças nos demais setores sociais. Como a educação pode utilizar as tecnologias para promover o pensamento criativo, complexo ou pensamento computacional? A primeira resposta que a educação brasileira deu a esta questão foi a informatização das escolas.

Nos anos iniciais da década de 90, começou a informatização das escolas brasileiras, por meio da implantação dos laboratórios de informática - LABIN. Como resultado destas ações, as escolas passaram a ter LABIN com número insuficiente de computadores para o número de alunos por turma, sem manutenção e, principalmente, sem projetos para capacitação da equipe escolar, para seu uso. Assim, subutilizados, com o passar do tempo, os computadores também se tornaram ultrapassados e, muitas vezes, sucateados. Nos anos subsequentes, novos programas e projetos enfatizaram a formação dos professores, o que em si já significou grande avanço, pois o trabalho

centrado na pessoa do professor e na sua experiência é particularmente relevante nos períodos de crise e de mudança, pois uma das fontes mais importantes de estresse é o sentimento de que não se dominam as situações e os contextos de intervenção profissional (NÓVOA, 1991, p.71). 


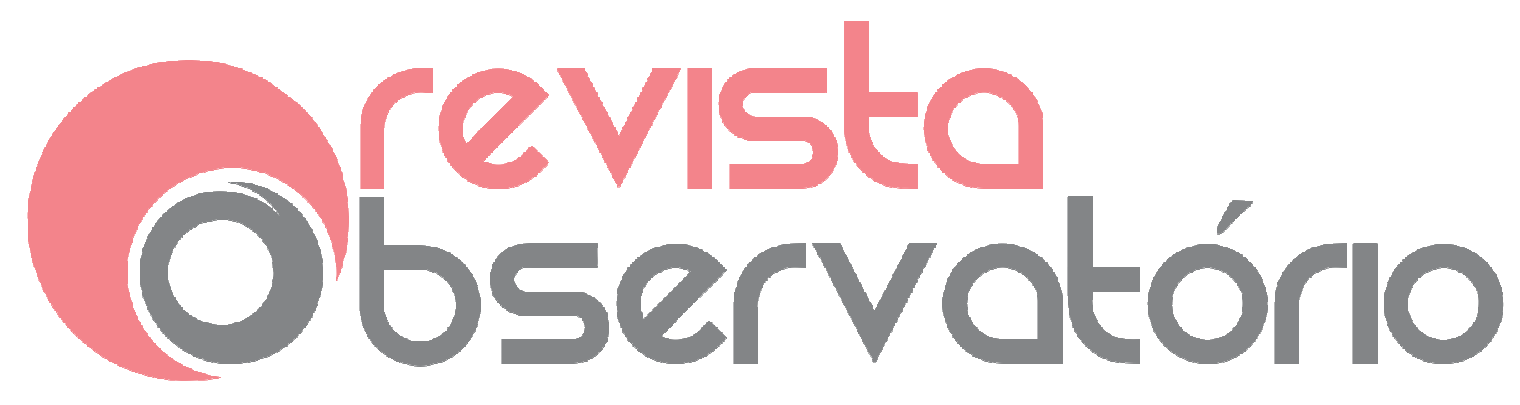

ISSN n² 2447-4266

Vol. 5, n. 1, Janeiro. 2019

DOI: http://dx.doi.org/10.20873/uft.2447-4266.2019v5n1p455

Concordando com Nóvoa, as mudanças via informatização das escolas são inviáveis sem a participação ativa dos professores, portanto torna-se fundamental o investimento em sua formação.

Nos anos 2000, sem perder o foco na formação docente, nova vertente da informatização das escolas incorporou as mudanças decorrentes da mobilidade dos computadores portáteis disponibilizados aos alunos.

Passadas várias décadas, o que pode ser presenciado nas escolas é que os computadores continuam subtilizados, as conexões com a internet muito lentas e todos os recursos digitais sendo usados mais para o entretenimento ou para melhorar a "motivação dos alunos" e muito raramente para a aprendizagem. Salvo honrosas exceções, as aulas permanecem tais e quais eram antes da "pseudo" informatização das escolas.

Neste contexto, diante de toda a revolução social gerada pela expansão das TDIC, parece que os educadores sentem a necessidade da mudança, mas nem sempre conseguem definir the o rumo. Ou, nas palavras de Nóvoa (2009, p.27) "há momentos em que parece que todos dizemos o mesmo, como se as palavras ganhassem vida própria e se desligassem da realidade das coisas". Nesta ótica, falar em uso integrado das tecnologias ao currículo escolar, discurso que já virou lugar comum entre os educadores, precisa ser ressignificado. É preciso passar do discurso à prática mediante mudanças conceituais e atitudinais. É preciso compromisso técnico e político com a mudança.

Nesta perspectiva, o papel da universidade na formação contínua de professores para e com o uso integrado das tecnologias ao currículo escolar, 


\section{Observatório \\ ISSN n² 2447-4266 \\ Vol. 5, n. 1, Janeiro. 2019 \\ DOI: http://dx.doi.org/10.20873/uft.2447-4266.2019v5n1p455}

tornou-se objeto de interesse de um grupo de docentes na Universidade Federal do Tocantins. Cientes que boa parte dos docentes em atividade concluiu sua formação na era analógica, e mesmo os mais jovens passaram por instituições educativas que não acompanharam a evolução das TDIC tal como ocorreu nos demais setores produtivos, este grupo assumiu um compromisso social de oferecer formação contínua aos educadores interessados na integração das tecnologias digitais a suas práticas. Dentre as ações de formação docente, uma das demandas encontradas pelo grupo foi a capacitação para produção e edição de videoaulas para os cursos mediados pelas tecnologias ou na modalidade híbrida.

Este trabalho descreve o processo, desde a criação do estúdio até os resultados da formação de uma turma piloto. Para tal, fundamenta-se no conceito de Pensamento Computacional - PC para enumerar e descrever os softwares livres, adotados na experiência de produção e edição das videoaulas, a baixo custo e de forma independente, pelos professores; Abordar as possibilidades de utilização de equipamentos comuns ao dia a dia de cada cidadão e provocadores da curiosidade nos alunos, as tecnologias digitais; Discutir a necessidade de formar professores para diminuir a distância entre o conhecimento dos recursos tecnológicos entre alunos e professores. Por fim, apresentar os resultados obtidos com a formação da primeira turma participante do "Projeto de Formação para a Integração Curricular das Tecnologias Digitais".

\section{Desenvolvimento do Pensamento Computacional}




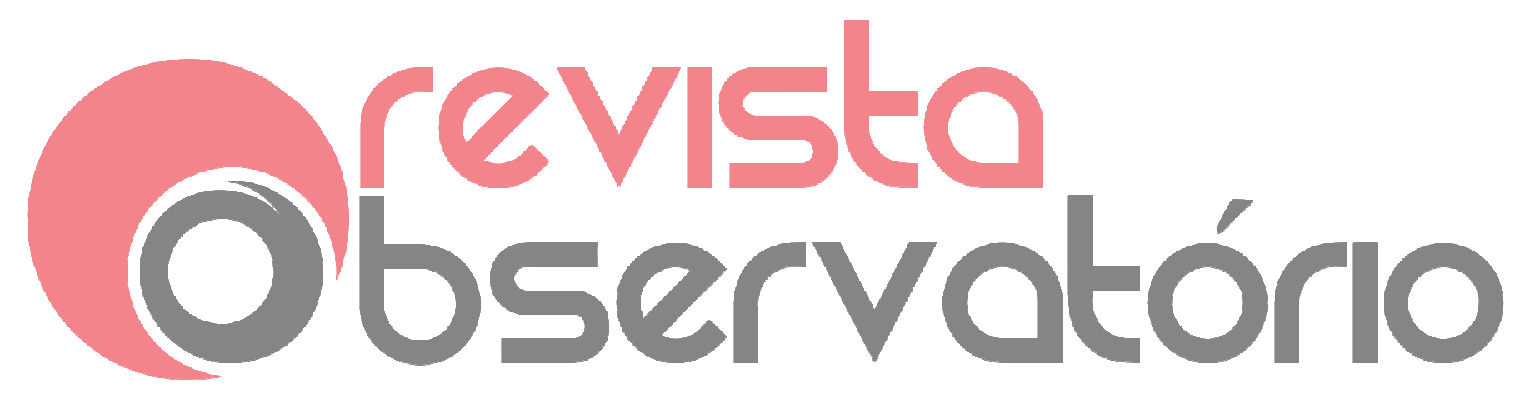

ISSN n² 2447-4266

Vol. 5, n. 1, Janeiro. 2019

DOI: http://dx.doi.org/10.20873/uft.2447-4266.2019v5n1p455

O uso dos editores de áudio e vídeo parece brincadeira para os jovens, adolescentes e crianças nascidos na era digital, mas nem sempre é possível dizer o mesmo em relação a seus professores. Além disso, é preciso considerar que uma coisa é saber usar tais editores no cotidiano, outra é usá-los como recursos pedagógicos ou ferramentas cognitivas, em que o uso é planejado intencionalmente para ajudar o desenvolvimento do pensamento complexo, crítico e criativo dos alunos (JONASSEN, 2007; ELHAJJ; ESCUDERO, 2016; MOURA, 2017; SPINELLI; SANTOS, 2018) ou do pensamento computacional, que "envolve o resolver problemas, conceber sistemas e compreender o comportamento humano, recorrendo aos conceitos fundamentais para a ciência da computação" (WING, 2006, p. 33). Entende-se que o verdadeiro uso educacional das TDIC ocorre quando estas são usadas de forma integrada ao currículo, para desenvolver atividades que não seriam possíveis sem elas.

Este uso integrado coincide com a forma que o conceito de $\mathrm{P} C$ vem sendo utilizado na atualidade, para referir-se aos processos mentais desenvolvidos pelos indivíduos na resolução de problemas, recorrendo, dentre outras habilidades, às estratégias da lógica de programação e uso de outros recursos computacionais. (BARCELOS et al, 2015; SILVEIRA JUNIOR, 2015; CHIECHER et al, 2016).

Para tal integração, faz-se necessário diminuir a distância entre a intimidade dos professores e dos alunos, com os recursos computacionais (LOPES; PEREIRA; MOURA, 2015; MIRANDA-PINTO; MONTEIRO; OSÓRIO, 2017). E esta é a meta de um grupo de professores da Universidade Federal do Tocantins, campus de Gurupi, ao propor e desenvolver o "Projeto de Formação para a Integração Curricular das Tecnologias Digitais". 


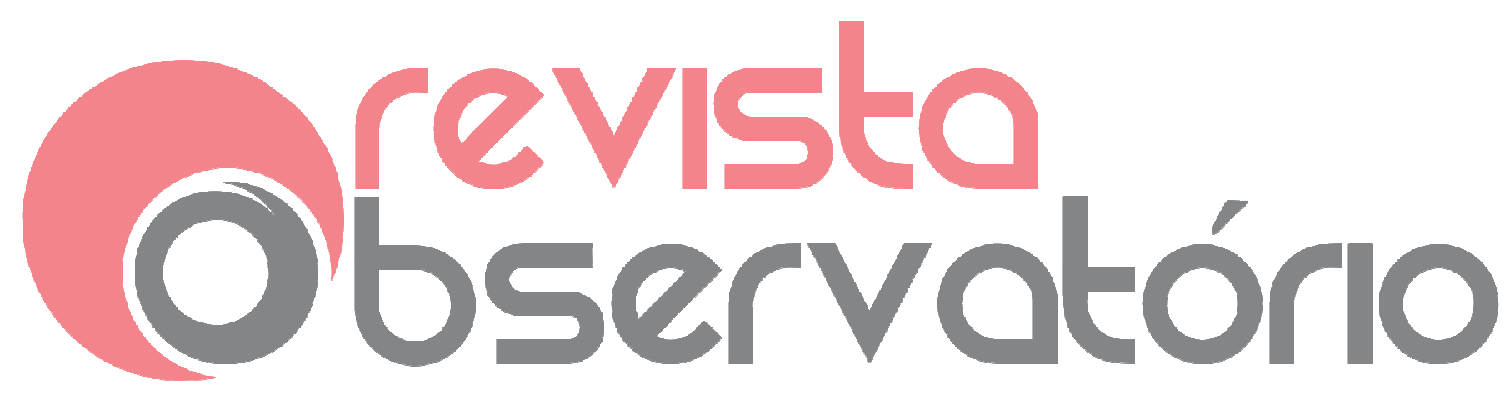

ISSN n² 2447-4266

Vol. 5, n. 1, Janeiro. 2019

DOI: http://dx.doi.org/10.20873/uft.2447-4266.2019v5n1p455

No bojo deste projeto, foi adaptado um estúdio para a produção e edição de materiais digitais de aprendizagem, numa sala de reuniões usada para o Laboratório Interdisciplinar de Formação de Educadores - LIFE. Esta já contava com alguns recursos tecnológicos: uma lousa digital, uma TV 50, um computador e um projetor multimídia. Com a necessidade de uso do espaço para apoio aos professores na produção de videoaulas, a tais recursos foram agregados equipamentos como tripés, suportes para celular, refletores, manufaturados com canos de PVC, papelão e outros matérias alternativos. (FIGURA 1).
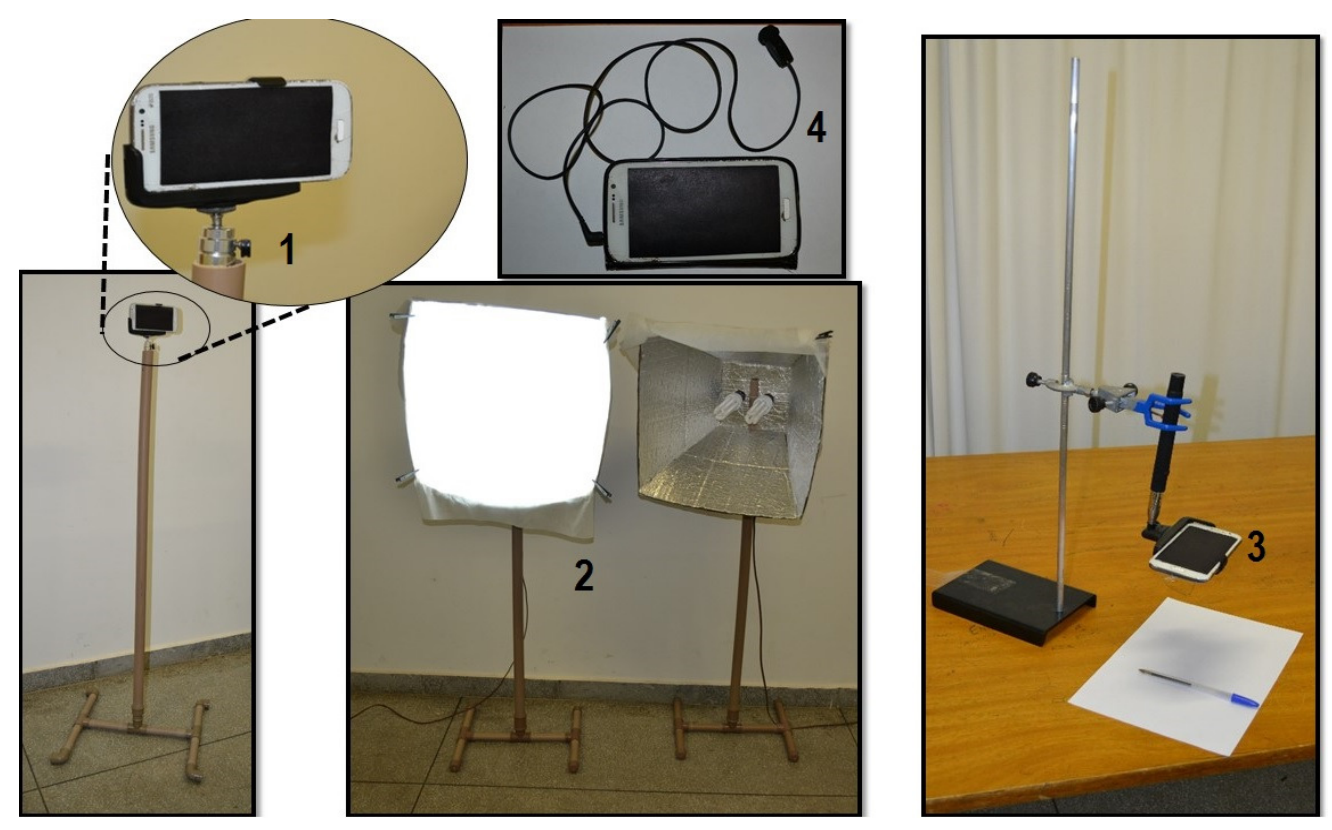

Figura 1- Equipamentos manufaturados para compor o Estúdio Multimídia. - Fonte: Os autores (2017)

Legenda: 1 - Tripé para gravação usando celular; 2 - Tripés e refletores; 3-Garra para gravação da mesa/escrita do professor; 4-Celular mais fone de ouvido (headphones) na função de microfone externo. 


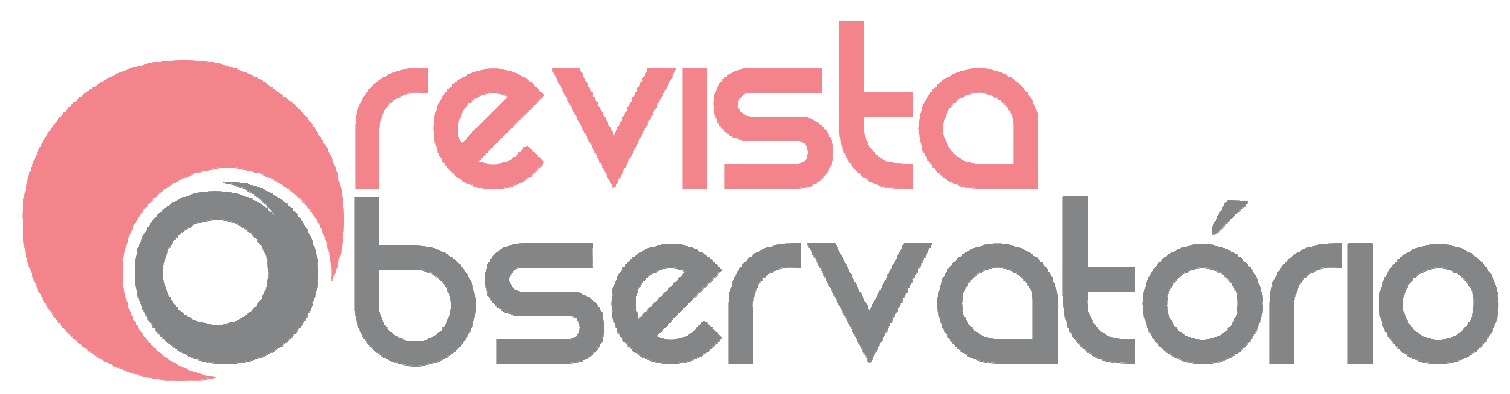

ISSN n² 2447-4266

Vol. 5, n. 1, Janeiro. 2019

DOI: http://dx.doi.org/10.20873/uft.2447-4266.2019v5n1p455

Estes equipamentos manufaturados deram apoio ao uso integrado do computador, celular, TV e lousa Digital. (FIGURA 2).

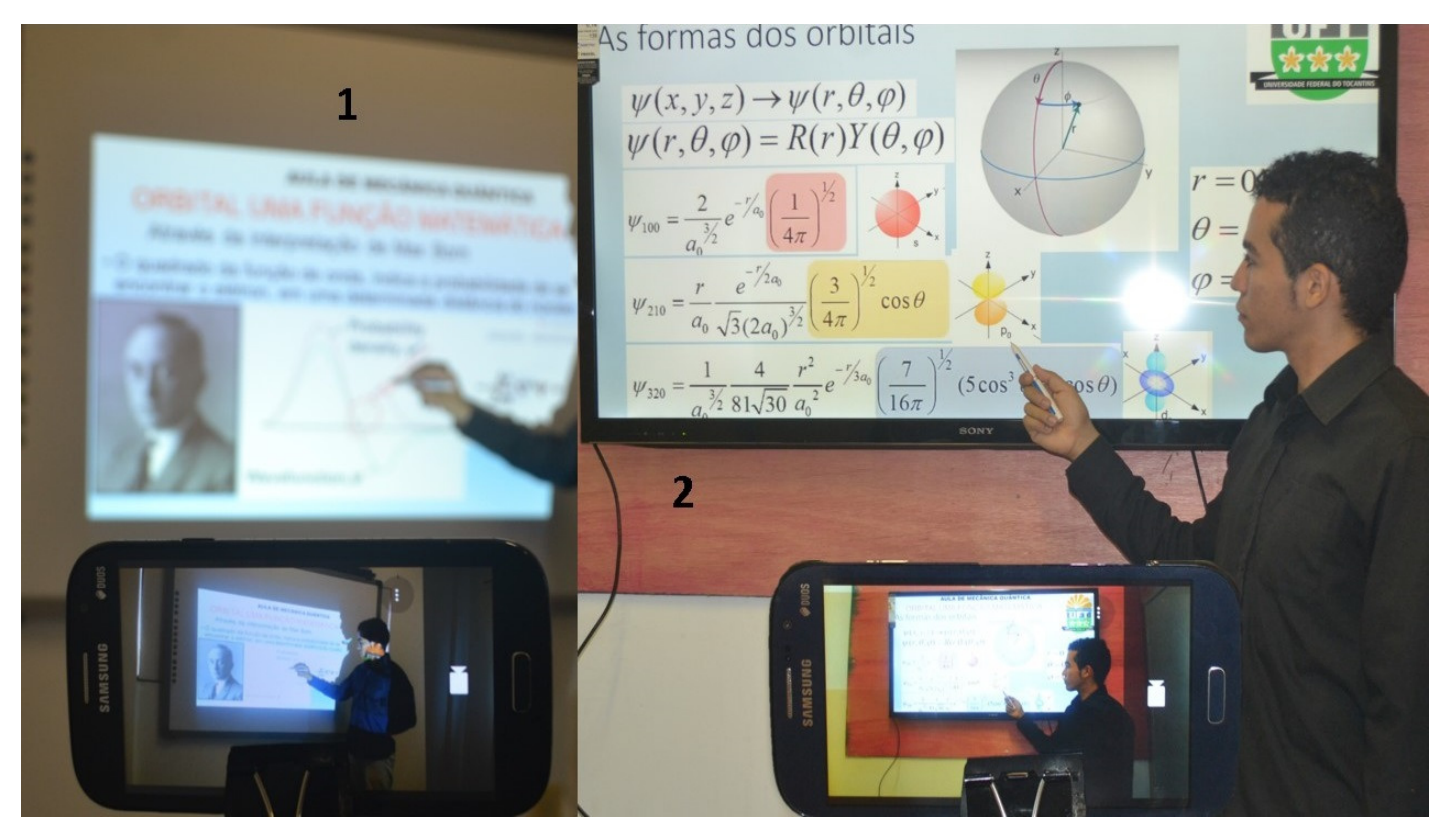

Figura 2 - Integração celular-lousa digital ou celular-TV. Fonte: Os autores (2017)

Legenda: 1 - Celular com enquadramento sobre a lousa digital; 2- Celular com enquadramento sobre a TV.

Além dos equipamentos (hardwares), também foi realizada uma busca e seleção de softwares livres, de código aberto e /ou shareware, para utilização junto aos softwares comerciais, como os editores do Microsoft Windows, adquiridos e instalados nas máquinas dos próprios professores, mas geralmente pouco utilizados como recurso didático-pedagógico. Tais softwares permitiriam a produção de materiais, a baixo custo e de forma independente, pelos professores. 


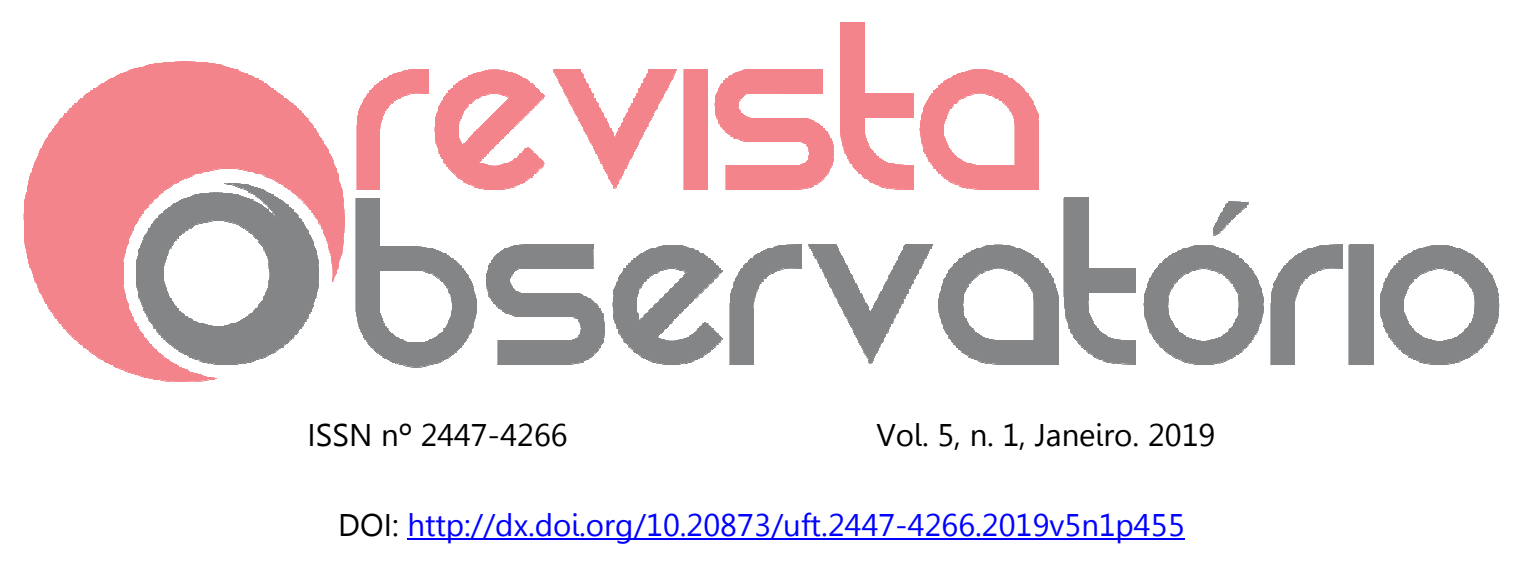

\section{Uso Educacional de softwares livres}

Como explica Branco (2006), o termo software livre se origina do inglês free software, fato que pode causar certa confusão, pois a palavra free tanto pode ser entendida como se referindo a questão de liberdade como à de gratuidade. Nesta mesma vertente, Silva (2016), explica que o software livre não é gratuito, ele se caracteriza pela liberdade existente na manipulação do código fonte podendo ser apenas consultado, como também alterado. Uma vez alterado, ele poderá ser redistribuído de forma gratuita ou não, enquanto o freeware indica que o software é gratuito, contudo o código fonte pode não ser disponibilizado junto ao aplicativo (executável ou binário).

Por outro lado, existem os softwares opensource ou de código aberto, que são os verdadeiramente livres, pois o executável/binário é disponibilizado juntamente com o código fonte da aplicação. Também existe o software shareware que é aquele disponibilizado na forma limitada, para demonstração de um item desenvolvido. Esta limitação pode relacionar-se a redução do tempo de utilização (geralmente 30 dias), ou à algumas funcionalidades.

Vários softwares destes tipos estão disponíveis na rede e podem ser empregados para produção de objetos digitais de aprendizagem, sem gerar ônus para o professor ou para a instituição. Exatamente o oposto do que ocorreria com o emprego de software proprietário, que concede direitos exclusivos ao produtor.

De fato, a produção de videoaulas no âmbito das instituições públicas depara com a questão dos custos. Não é possível adquirir softwares (assim como qualquer outro produto ou serviço) sem uma boa dose de burocracia. 


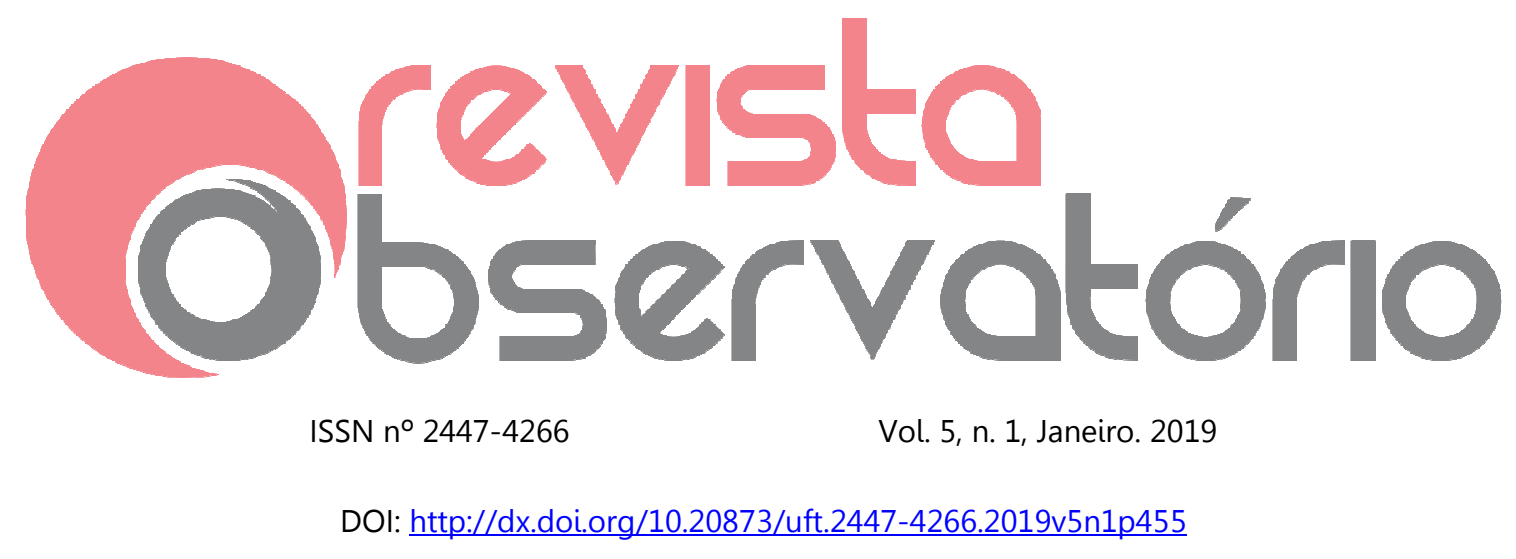

Uma alternativa é utilizar os softwares de cunho livre e softwares que permitem acesso as suas funcionalidades, sem restrições quanto as suas principais funções e também softwares (aplicativos) que adéquam melhor ao uso do celular, na produção das videoaulas.

\section{Softwares para produção de videoaulas a baixo custo}

Para o uso com e pelos professores foi realizada uma busca criteriosa e testagem, de vários softwares livres, resultando na seleção dos seguintes:

1. ActivePresenter (freeware)- É um software que permite a gravação da tela do computador.

2. Camdesk (Opensource) - É um software que possibilita ter a imagem, filmada pela webcam, sempre visível na tela do computador, independe se o operador estiver usando outro software. Também é possível fazer a integração deste software com um de captura da tela do computador.

3. Open câmera app (Opensource) - É um aplicativo do tipo gravador de vídeo, com recurso de gravação em resolução fullHD, além de permitir controle do foco da câmera filmadora do celular. Este tipo de aplicativo é bastante interessante para gravar vídeos externos para a integração de outras mídias à videoaulas como, por exemplo, a TV. Pode, também, ser uma alternativa para a inclusão da demonstração, por exemplo, da resolução de exercícios, em uma videoaula de exatas. Isto pode ser feito, por meio do uso do celular para a filmagem da mão resolvendo os cálculos.

4. Recforge2 app (livre) - É um aplicativo do tipo gravador de áudio para celular em formato wave. Assim, um celular colocado no bolso e acoplado 


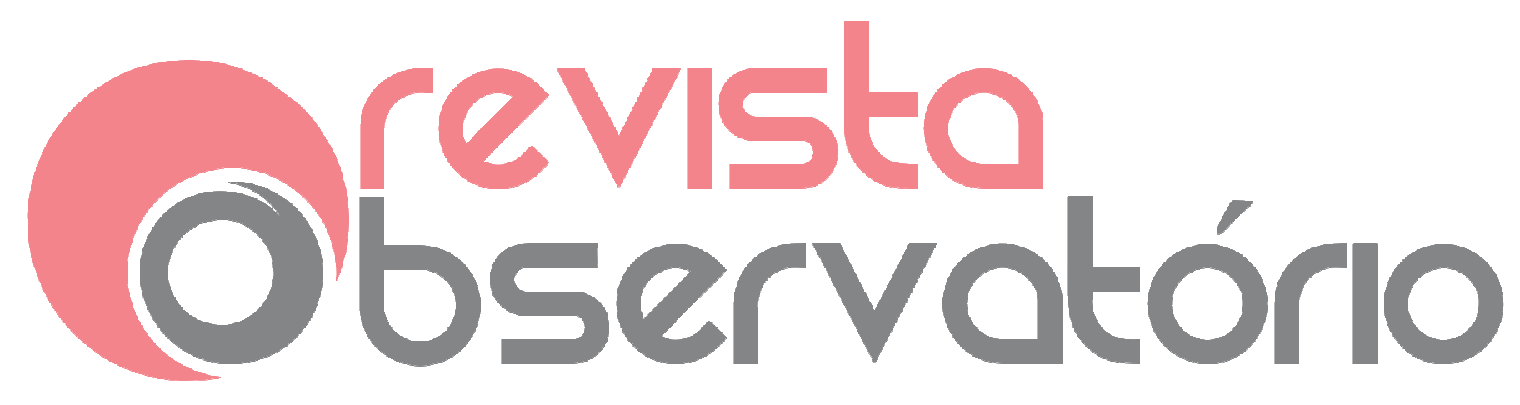

ISSN n² 2447-4266

Vol. 5, n. 1, Janeiro. 2019

DOI: http://dx.doi.org/10.20873/uft.2447-4266.2019v5n1p455

a um fone de ouvido com microfone, capta o áudio da explicação do professor do processo de resolução do exercício. É importante lembrar que este tipo de aplicativo, se usado juntamente com um microfone de lapela, deixará o som da videoaula com mais qualidade e facilitará o trabalho de edição.

Mas, para a produção das videoaulas, também seriam necessários softwares para edição. Assim, a mesma metodologia, de busca e testagem, foi realizada em relação aos softwares para edição das videoaulas, resultando nos seguintes:

1. Audacity (opensource) - Com este software é possível retirar ruídos do áudio gravado.

2. Video pad (shareware) - Este software é um editor básico de vídeos. Ele possui a vantagem de ser fácil manuseio e possuir tamanho pequeno, podendo ser instalado mesmo em computadores com baixa configuração.

Estes softwares foram instalados, inicialmente no computador do LIFE, entretanto, ao começar as formações em grupos, foram apresentados aos professores e instalados em seus computadores pessoais.

\section{Formação para a Integração Curricular das Tecnologias Digitais}

Organizado o ambiente e os recursos, as ações de formação puderam se expandir de experiências individualizadas (geralmente atendendo a uma urgência na produção de materiais para as disciplinas em curso) para a realização de oficinas, minicursos e cursos com grupos de professores, objeto do Projeto Formação para a Integração Curricular das Tecnologias Digitais. 


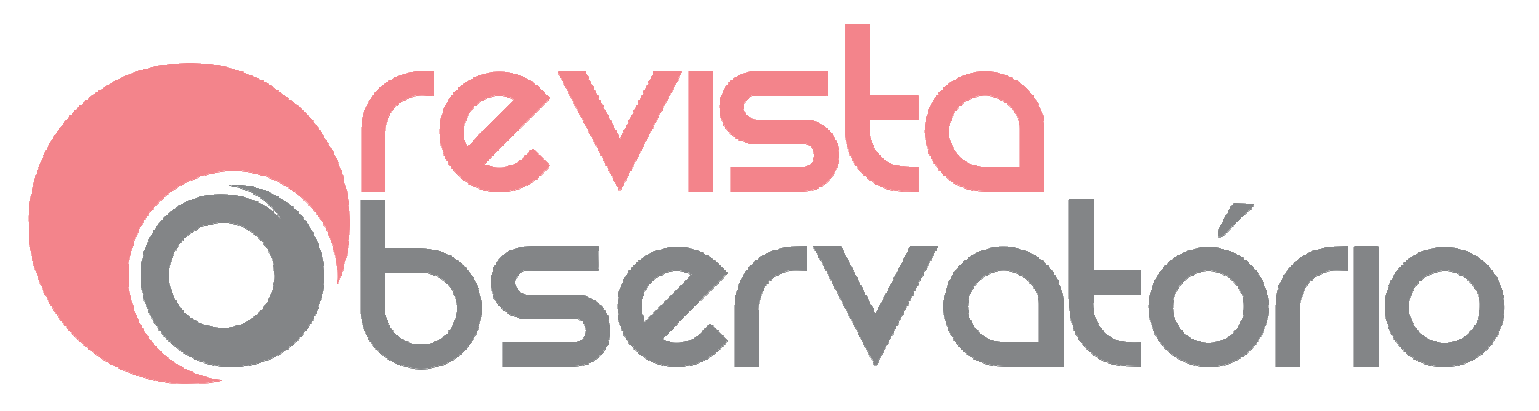

ISSN n² 2447-4266

Vol. 5, n. 1, Janeiro. 2019

DOI: http://dx.doi.org/10.20873/uft.2447-4266.2019v5n1p455

O referido projeto tem como objetivo geral ofertar vivências para a formação continuada de docentes, das redes públicas (municipal, estadual e federal) de Gurupi e região, para a integração curricular das Tecnologias Digitais da Informação e Comunicação (TDIC). Propõe que tais vivências sejam planejadas e desenvolvidas de forma compartilhada com o público alvo de cada atividade (oficina, minicurso ou curso), delineadas a partir de diagnóstico realizado com representantes de cada segmento envolvido, a saber: professores, gestores, coordenadores pedagógicos e de TIC em atividade nas instituições de ensino.

Os resultados esperados englobam a realização de pelo menos dois cursos semestrais, na modalidade híbrida, e a consequente integração entre universidade e escolas de educação básica. A expectativa é que tais práticas sirvam de ponto de partida para a integração curricular das tecnologias digitais, a partir da criação de uma rede de aprendizagem e de compartilhamento de práticas educativas com o uso das TDIC, desenvolvida pelos diferentes atores envolvidos nas ações de formação, bem como por seus pares.

Para garantir a construção compartilhada de conhecimentos sobre as TDIC, desde o início, os cursos foram pautados na participação de todos. Inicialmente foi identificada a demanda de conhecimento de softwares livres e recursos que podem ser usados livremente pelos professores para produção de videoaulas e objetos de aprendizagem para seus alunos. Os professores reclamam que, a produção de materiais didático-pedagógicos, além de demandar muito tempo, esbarra na limitação dos recursos, visto que os melhores softwares são pagos. 


\section{Observatório \\ ISSN n² 2447-4266 \\ Vol. 5, n. 1, Janeiro. 2019 \\ DOI: http://dx.doi.org/10.20873/uft.2447-4266.2019v5n1p455}

$\mathrm{Na}$ expectativa de proporcionar espaço permanente para experiências de produção de videoaulas, foi criado o estúdio improvisado de multimídia, utilizando plataformas gratuitas, softwares livres e mecanismos manufaturados com aproveitamento de materiais alternativos, conforme descrição anterior. Assim foi desenhado o primeiro curso de produção e compartilhamento de videoaulas, usando equipamentos disponíveis na universidade (computador, TV, lousa digital), outros do próprio professor (laptops e celulares) e outras tecnologias de baixo curso, destacando-se os materiais manufaturados e os softwares livres.

Em 2016, esse primeiro curso, denominado "Uso Pedagógico das Tecnologias Digitais da Informação e da Comunicação - TDIC" foi configurado, com a seguinte ementa: Exploração de recursos e ferramentas tecnológicas, com ênfase em softwares livres, para integração ao currículo escolar, nos diferentes níveis de ensino. Inicialmente foi ofertado à turma denominada piloto composta por educadores em atividade na secretaria municipal de educação de Gurupi, que voluntariamente se inscreveram para um curso de modalidade híbrida, com carga horária total de sessenta (60) horas aula, sendo apenas doze (12) horas aulas presenciais, em dois (2) encontros, intercalados por atividades a distância.

Para o intervalo entre o primeiro e segundo encontros presenciais, 0 cursista deveria escolher um conteúdo, de qualquer componente curricular (preferencialmente interdisciplinar), selecionar uma ou mais funções do Excel e planejar uma aula, com o uso de TDIC. Após o segundo encontro, cada cursista deveria, dentre os conteúdos estudados no curso, escolher uma ou mais 


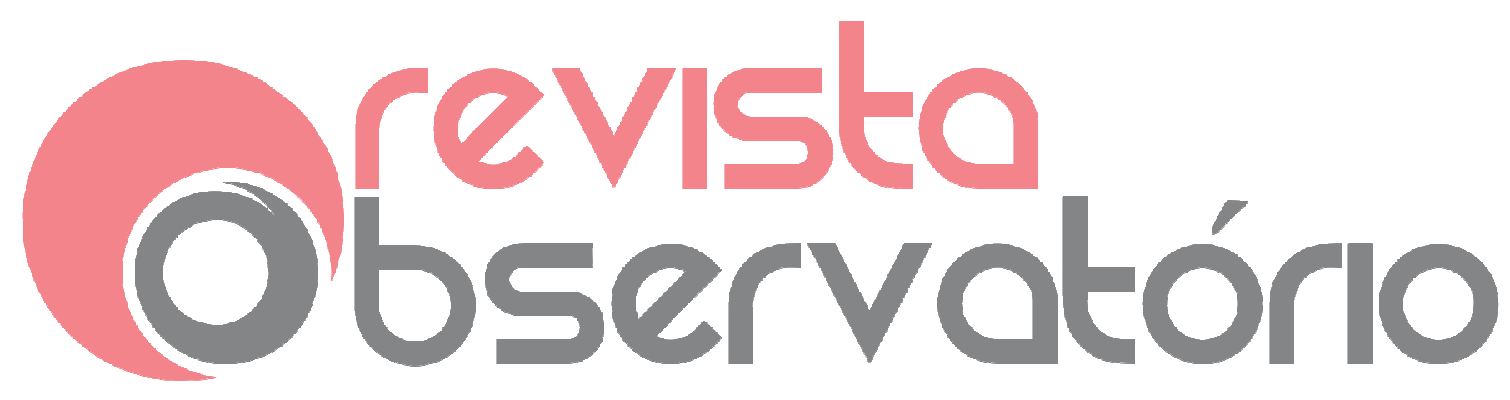

ISSN n² 2447-4266

Vol. 5, n. 1, Janeiro. 2019

DOI: http://dx.doi.org/10.20873/uft.2447-4266.2019v5n1p455

ferramentas tecnológicas e produzir e compartilhar uma videoaula sobre um tema de seu interesse.

Durante todo o período do curso os cursistas, professores e moderadores interagiram por meio do grupo criado no whatsApp. Os resultados apresentados e discutidos, neste trabalho, referem-se somente a esta primeira turma.

\section{Resultados e Discussão}

Destaca-se que a produção de videoaulas demanda o conhecimento dos softwares para produção e edição de áudio e de vídeo. Demanda a escolha dos mais adequados ao contexto e necessidades, mas demanda, sobretudo, a capacidade do professor utilizar tais recursos para a produção de materiais desafiadores do pensamento criativo de seus alunos. Ou seja, não se trata de transpor a aula presencial expositiva para a videoaula.

Neste sentido, a formação para a integração curricular das TDIC, conta com o espaço físico e recursos adaptados, graças à criatividade brasileira. Mais que demonstrar os softwares selecionados e sua utilização, os cursos ofertados propõem a reflexão dos cursistas sobre o uso de tais recursos para desenvolver atividades educativas desencadeadoras do pensamento computacional, atividades com o uso das tecnologias digitais, que não seriam possíveis sem o seu uso. Propõem também atividades práticas, em que os cursistas façam a transposição dos cursos para suas práticas enquanto professores. 


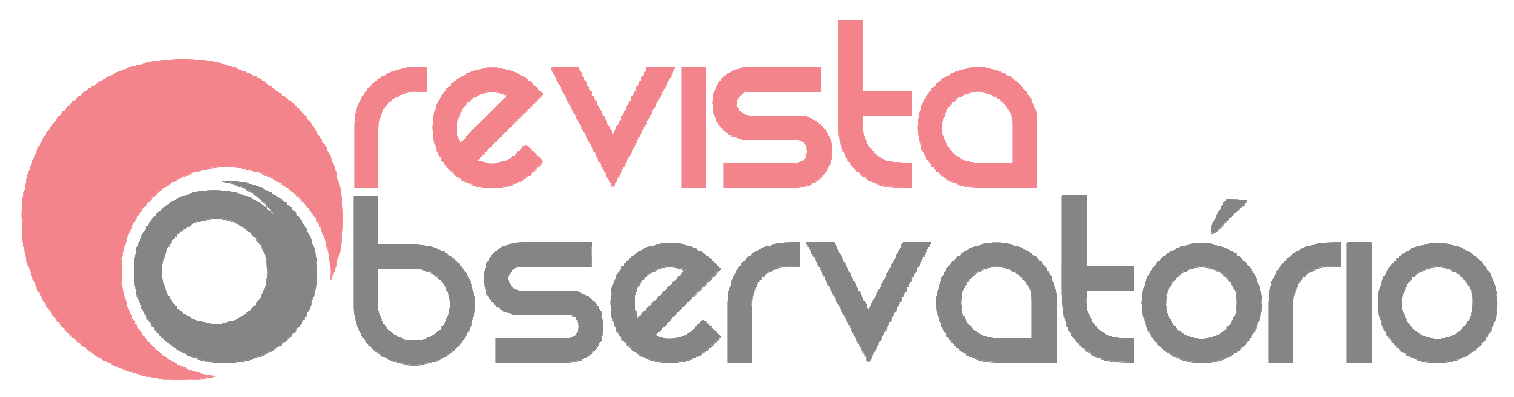

ISSN n² 2447-4266

Vol. 5, n. 1, Janeiro. 2019

DOI: http://dx.doi.org/10.20873/uft.2447-4266.2019v5n1p455

O uso conjunto destes softwares permitiu a edição de videoaulas (FIGURA 3) que, se não atendem a todos os requisitos, dão indícios de que podem fazê-lo, se ainda não em relação aos alunos público alvo de tais videoaulas, em relação aos professores produtores.

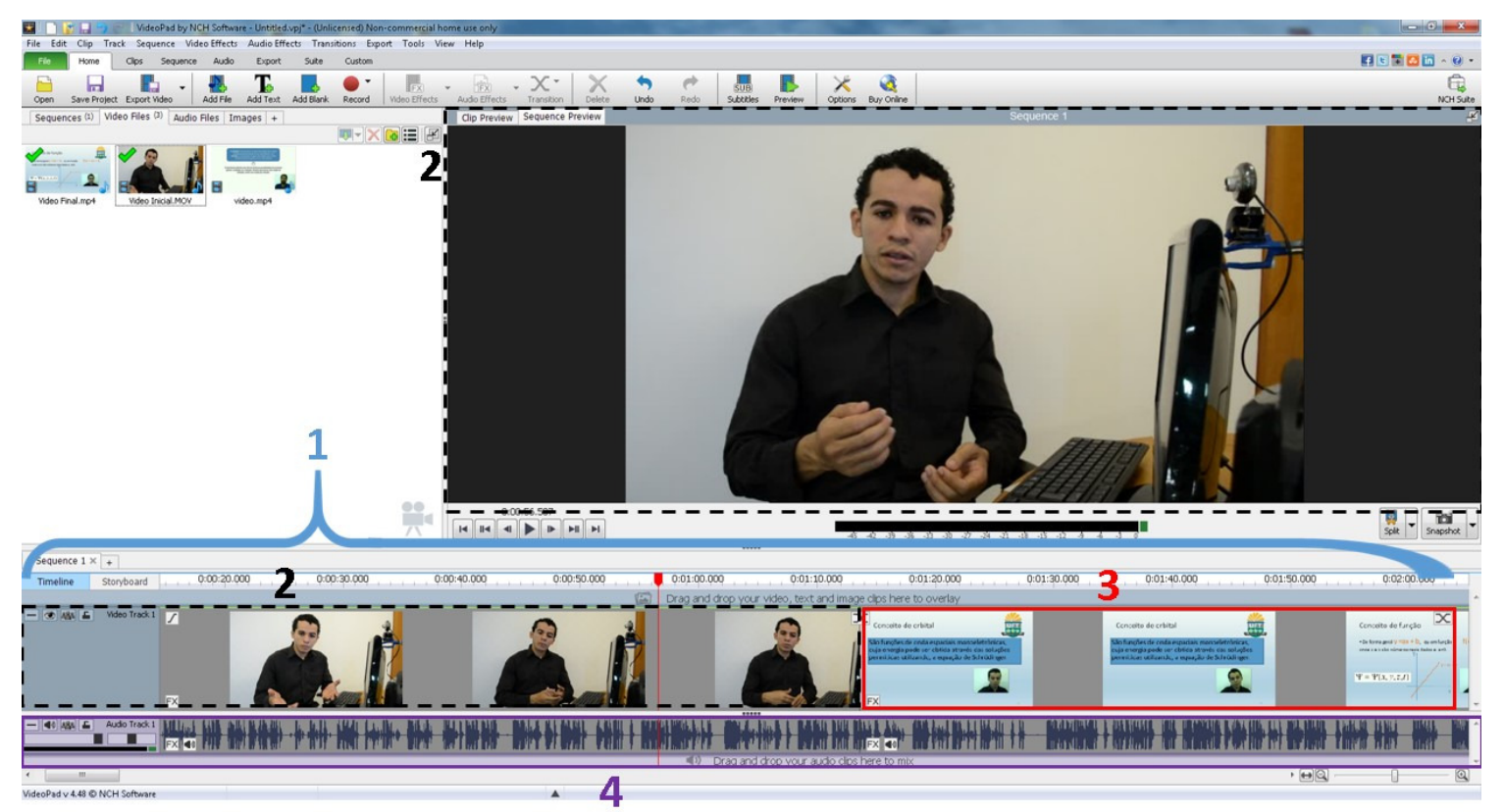

Figura 3 - Edição de videoaula, usando o Videopad - Fonte: Os autores (2017)

Legenda: 1- Timeline de edição dos vídeos; 2- vídeo inicial de abertura capturado por uma câmera externa ou uma câmera de um celular com Open câmera app; 3 -vídeo da captura da tela do computador pelo ActivePresenter integrado o Camdesk com a função de mostrar o rosto do professor com a webcam; 4 -Timeline do áudio capturado pelo Recforge2 app e tratado pelo Audacity.

Assim, as demandas para formação estão chegando e serão atendidas à medida das necessidades de cada grupo. Os materiais poderão ser alterados, acrescidos ou substituídos, mas eixo teórico-metodológico, norteador de todas as formações deve ser o uso dos recursos tecnológicos para o desenvolvimento 


\section{Observatório \\ ISSN n² 2447-4266 \\ Vol. 5, n. 1, Janeiro. 2019 \\ DOI: http://dx.doi.org/10.20873/uft.2447-4266.2019v5n1p455}

do pensamento computacional, em tudo que ele tem de complexo, crítico e criativo.

As videoaulas produzidas pela turma piloto possuem relativa qualidade técnica, compatível para o uso pelos alunos, mesmo que a banda de sua internet não seja das melhores, como é a realidade nos municípios interioranos.

Como o projeto encontra-se em andamento, apenas uma turma piloto concluiu suas atividades de produção de videoaulas. A segunda turma encontra-se na fase de produção para posterior compartilhamento.

Novas turmas estão se constituindo, entre professores que atuam nos cursos mediados pelas tecnologias e professores que atuam em cursos presenciais, na universidade. Também serão abertas novas turmas para os professores da educação básica, em atividade nas redes públicas municipal e estadual. A partir das lições aprendidas com a turma piloto, para as novas turmas foram mantidos o princípio da formação híbrida e da coparticipação dos sujeitos em todas as fases da formação, desde o seu planejamento até a avaliação final.

Ao final das atividades da turma piloto, aproximadamente $75 \%$ dos cursistas conseguiu produzir uma videoaula, de forma autônoma, o que foi considerado como quesito indispensável à certificação. Tais produções foram publicadas em uma página do facebook, criada para compartilhamento das experiências de formação, no contexto da capacitação para produção e edição de videoaulas, assim como de outras ações de formação para a integração curricular das TDIC. 


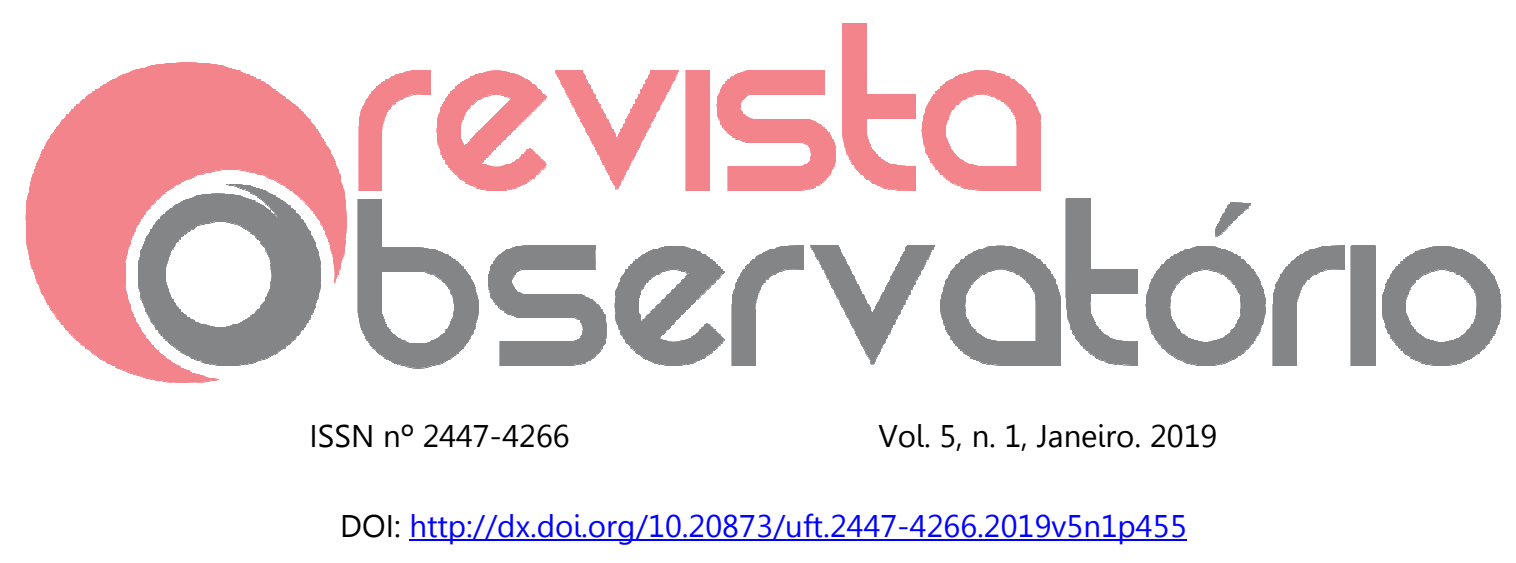

\section{Considerações Finais}

A integração das mídias digitais na educação brasileira carece da constituição de políticas públicas sérias e comprometidas com um processo de médio e longo prazo, no lugar de projetos pontuais e descontínuos de "informatização das escolas". Além disso, é preciso conjugar ações voltadas para a aquisição, manutenção e reposição de hardwares e softwares, com ações de formação continuada dos profissionais da educação.

Entretanto, enquanto tais políticas não veem, tal integração pode se acontecer no âmbito das instituições educacionais, pela iniciativa do corpo docente e técnico comprometido com uma educação significativa e coerente com a sociedade contemporânea, permeada pela cultura digital.

O uso de softwares livres e de materiais alternativos, como exposto neste trabalho, parece uma alternativa viável para obter resultados significativos, em curto prazo. Destaca-se que os resultados preliminares alcançados no Projeto de Formação para Integração Curricular das TDIC mostram que é possível fazer tal formação de forma contínua e que este é um desafio para as Universidades.

\section{Referências}

ALMEIDA, M. E. B. Integração currículo e tecnologias: concepção e possibilidades de criação de web currículo. In: ALMEIDA, M. E. B.; ALVES, R. M.; LEMOS, S. D. V. Orgs.) Web currículo. Aprendizagem, pesquisa e conhecimento com o uso de tecnologias digitais. Rio de Janeiro/RJ: Letra Capital, 2014.

ARROIO, A.; GIORDAN, M. (2006). O vídeo educativo: aspectos da organização do ensino. Química nova na escola, 24(1), 8-11. 


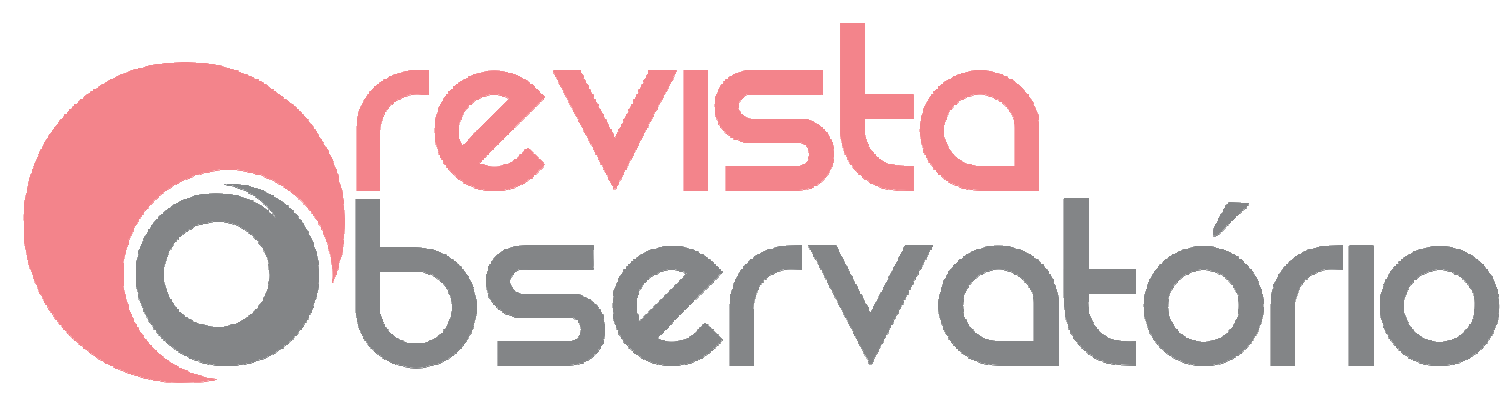

ISSN n² 2447-4266

Vol. 5, n. 1, Janeiro. 2019

DOI: http://dx.doi.org/10.20873/uft.2447-4266.2019v5n1p455

AZEVEDO JR, D. P.; RAMOS, M. S.; AZEVEDO, M. B. Roteirização de videoaulas para a educação on-line. In VI Congresso Brasileiro de Ensino Superior a Distância. São Luís, 2009. (pp. 1-10).

BARCELOS, T., MUÑOZ, R., ACEVEDO, R. V., \& SILVEIRA, I. F. (2015, October). Relações entre o pensamento computacional e a matemática: uma revisão sistemática da literatura. In Anais dos Workshops do Congresso Brasileiro de Informática na Educação. Octuber, 2015,Vol. 4, No. 1, pp. 1369-1378. http://dx.doi.org/10.5753/cbie.wcbie.2015.1369. Acesso: 17 Fev. 2017.

BARRÉRE, E. Videoaulas: aspectos técnicos, pedagógicos, aplicações e bricolagem. Jornada de Atualização em Informática na Educação, 2014, 3(1).

BARRÉRE, E., SCORTEGAGNA, L.; LÉLIS, C. A. S. Produção de Videoaulas para o Serviço EDAD da RNP. In Brazilian Symposium on Computers in Education (Simpósio Brasileiro de Informática na Educação-SBIE). Vol. 1, No. 1, 2011.

BRANCO, M. D. Sotware livre. Disponível em: <http://www.vecam.org/article710.html>. Acesso: 09 Mai. 2016.

BUCKINGHAM, D. Cultura Digital, Educação Midiática e o Lugar da Escolarização. Educação \& Realidade, Porto Alegre, v. 35, n. 3, 2010. p. 37-58, set./dez.,

Disponível:<http://seer.ufrgs.br/index.php/educacaoerealidade/article/view/130 77/10270> Acesso: 12 fev. 2016.

CASTELLS, M.. A sociedade em rede. São Paulo: Paz e Terra, 1999.

CHIECHER, A.; FICCO, C.; PAOLONI, P.; GARCÍA, G. ¿Qué mueve a los estudiantes exitosos? Metas y motivaciones de universitarios en las modalidades presencial y distancia. Revista Observatório, v. 2, n. 2, p. 301-326, 30 maio 2016. DOI: https://doi.org/10.20873/uft.2447-4266.2016v2especial1p301.

DOTTA, S. C.; JORGE, E. F.; PIMENTEL, E. P.; BRAGA, J. C. (2013). Análise das Preferências dos Estudantes no uso de Videoaulas: Uma experiência na Educação a Distância. In Anais do Workshop de Informática na Escola. Vol. 1, No. 1, p. 21, 2013. 


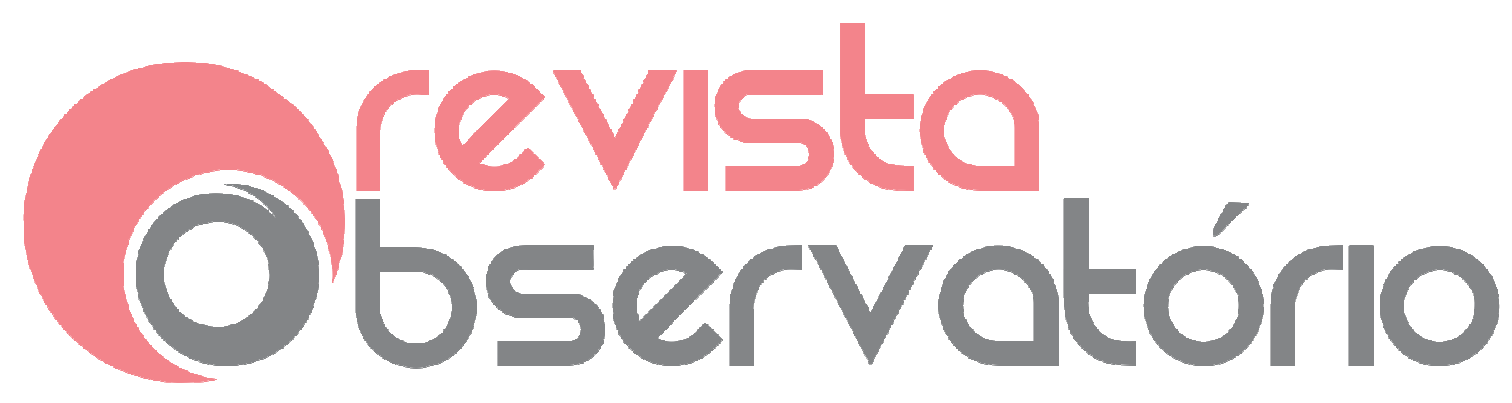

ISSN n² 2447-4266

Vol. 5, n. 1, Janeiro. 2019

DOI: http://dx.doi.org/10.20873/uft.2447-4266.2019v5n1p455

ELHAJJI, M.; ESCUDERO, C. WEBDIÁSPORA: Migrações, TICs e memória coletiva. Revista Observatório, v. 2, n. 5, p. 334-363, 25 dez. 2016. DOI: https://doi.org/10.20873/uft.2447-4266.2016v2n5p334

FIGUEIREDO, M. A.; SILVA, O. G.; COSTA, S. R. Programas de Nivelamento de Matemática e Português: M-Learning com Videoaulas. In: Congresso Internacional de Educação a Distância-ABED (Associação Brasileira de Educação a Distância), Manaus, 2011.

FLORIDI, L. The Onlife Manifesto. 2015. Being Human in a Hyperconnected Era. Springer Open. Disponível: $<$ https://www.academia.edu/9742506/The_Onlife_Manifesto_-

_Being_Human_in_a_Hyperconnected_Era>. Acesso: 20 mai. 2016.

HUBER, D. M.; RUNSTEIN, R. E. Técnicas modernas de Gravação de Áudio. Taylor \& Francis, 2011. Disponível em < https://www.livrebooks.com.br/livros/tecnicasmodernas-de-gravacao-de-audio-david-miles-huber-robert-e-runsteinpqco66gjcb8c/baixar-ebook> acesso em 17 Fev. 2017

JONASSEN, D. H. Computers in the classroom: mind tools for critical thinking. Columbus (OH): Prentice-Hall, 1996.

JONASSEN, D. H. Computadores, ferramentas cognitivas: desenvolver o pensamento crítico nas escolas . Porto/Portugal: Porto, 2007.

LOPES, P.; PEREIRA, S.; MOURA, P.; CARVALHO, A. Avaliação de competências de literacia mediática: o caso português. Revista Observatório, v. 1, n. 2, p. 42-61, 8 dez. 2015. DOI: https://doi.org/10.20873/uft.2447-4266.2015v1n2p42.

MACHADO, A. Pré-cinemas \& pós-cinemas. Papirus, 1997.

MIRANDA-PINTO, M.; MONTEIRO, A.; OSÓRIO, A. POTENCIALIDADES E FRAGILIDADES DE ROBÔS PARA CRIANÇAS EM IDADE PRÉ ESCOLAR: 3 A 6 ANOS. Revista Observatório, v. 3, n. 4, p. 302-330, 1 jul. 2017. DOI: https://doi.org/10.20873/uft.2447-4266.2017v3n4p302 


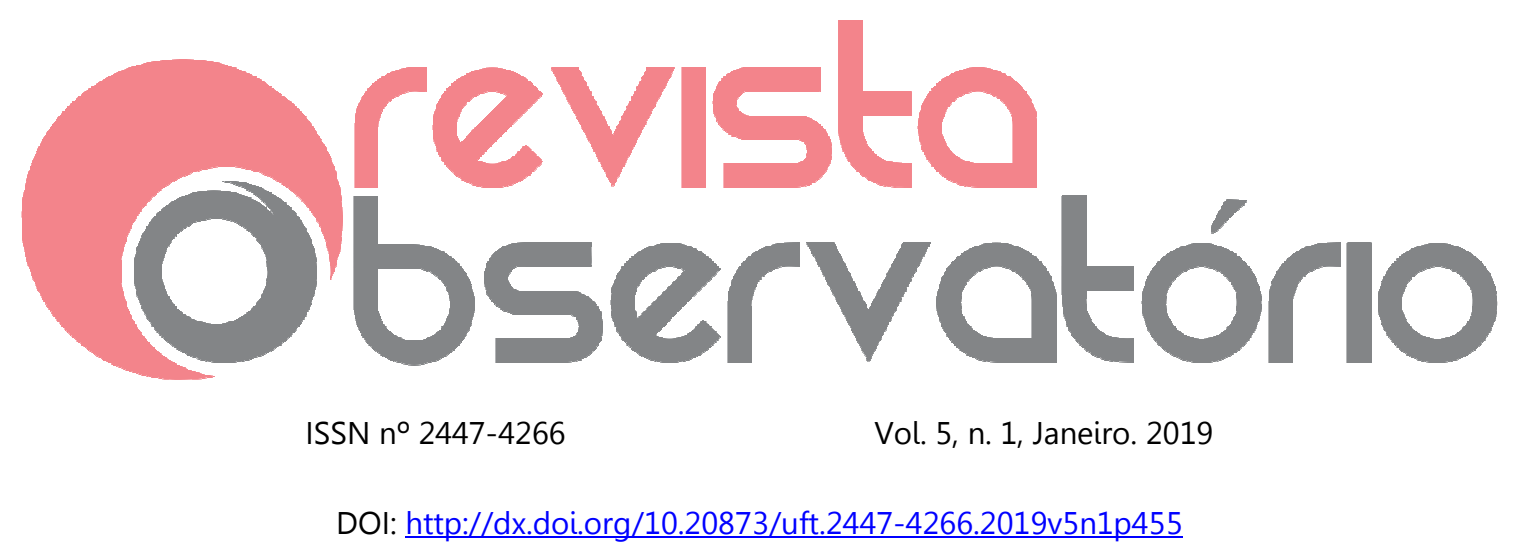

MORÁN, J. M. O vídeo na sala de aula. Comunicação \& Educação, 1995, (2), $27-$ 35. Disponível <https://www.livrebooks.com.br/livros/pre-cinemas-e-poscinemas-arlindo-machado-graayywgjgwc/baixar-ebook> Acesso: 17 Fev. 2017

MONTEIRO, D. C.; De PAIVA, J. E. R. O Áudio na Internet. MAV Ebook.

MOURA, A. METODOLOGIAS DE APRENDIZAGEM QUE DESAFIAM OS ALUNOS, MEDIADAS POR TECNOLOGIAS DIGITAIS. Revista Observatório, v. 3, n. 4, p. 256278, 1 jul. 2017. DOI: https://doi.org/10.20873/uft.2447-4266.2017v3n4p256.

MUSSIO, S C. Do presencial ao digital: um diálogo com o gênero videoaula youtubiano de escrita científica. Fronteiras-estudos midiáticos, v. 18, n. 3, p. 334-347, 2016.

NAKASHIMA, R. H.; DA SILVA, D. TECNOLOGIAS NO ENSINO DE HISTÓRIA: produção de recurso educacional aberto. Revista Observatório, v. 4, n. 6, p. 965984, 8 out. 2018. DOI: https://doi.org/10.20873/uft.2447-4266.2018v4n6p965.

NÓVOA, A. Formação de professores e profissão docente. 1991. Disponível em: <http://core.ac.uk/download/pdf/12424596.pdf>. Acesso: 20 abr. 2014.

NÓVOA, A. Professores. imagens do futuro presente. Lisboa/Portugal: Educa, 2009. Disponível

em: <http://www.etepb.com.br/arq_news/2012texto_professores_imagens_do_futuro_pre sente.pdf>. Acesso: 10 jan. 2015.

OLIVEIRA, M. H. D.; GONÇALVES, D. U. Video lesson or teleconsulting for family doctors learning otorhinolaryngology. Revista Brasileira de Educação Médica. 2012, 36(4), 531-535.

RAABE, A., BERNARDES, A.; JUNIOR, R. G. A. Produção e Avaliação de Videoaulas: Um Estudo de Caso no Ensino de Programação. In Anais do Workshop de Informática na Escola. 2014, Vol. 20, No. 1, p. 448.

RUBACK, S. P.; Da CRUZ, I. C. Elaboração de uma vídeo-aula sobre a automedida da pressão arterial para hipertensos: Um relato de experiência. Boletim NEPAENESEN, 2014, 11(2). 


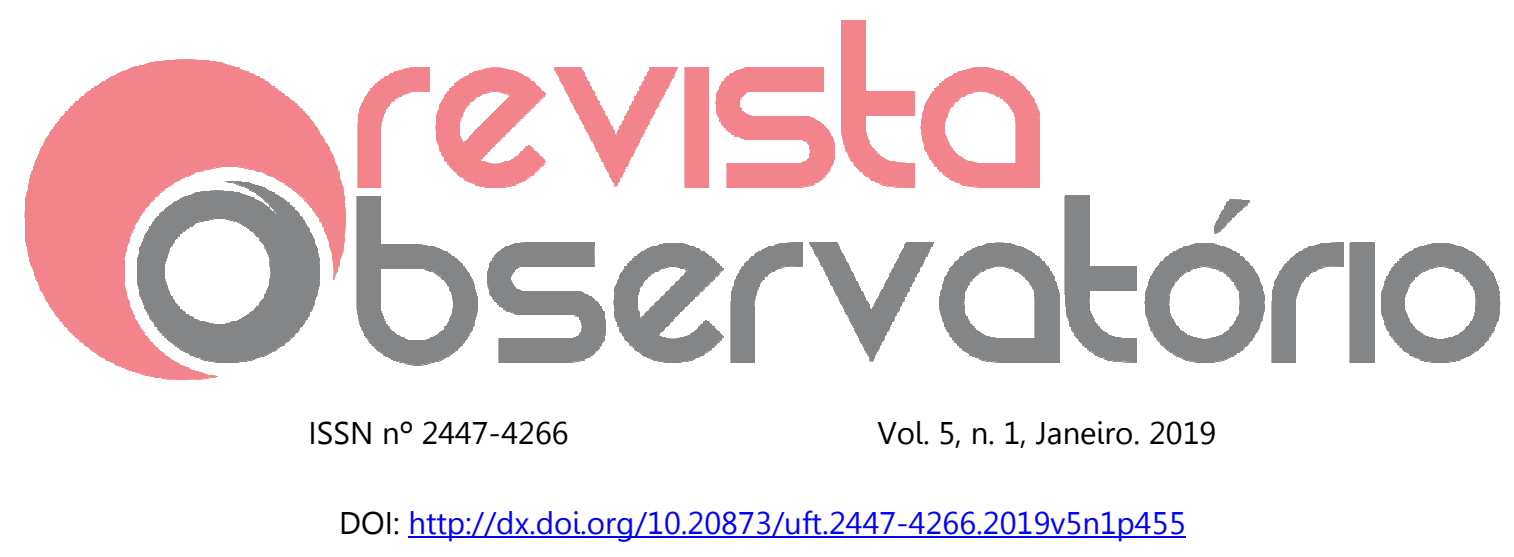

SILVA , F. A. C. O uso do sotware livre na educação básica na Escola Antônio Guedes. Caminho Aberto: Revista de Extensão do IFSC, ano 3, n 5 , novembro 2016. Disponível em: HTTPS://PERIODICOS.IFSC.EDU.BR/INDEX.PHP/CAMINHOABERTO/ARTICLE/VIEW/1935/ AcesSO: 20 jan. 2016.

SILVEIRA, S. A. Sotware Livre: a luta pela liberdade do conhecimento. São Paulo: Editora Fundação Perseu Abramo, 2004. Disponível em: <http://www2.fpa.org.br/uplo ads/Software_livre.pdf>. Acesso: 04 Out. 2016.

SILVEIRA JUNIOR, P. Teoria, conhecimento e pragmática da comunicação: o paradigma pulsional. Revista Observatório, v. 1, n. 2, p. 136-155, 8 dez. 2015. DOI: https://doi.org/10.20873/uft.2447-4266.2015v1n2p136.

SOFTWARELIVRE.ORG. Boas-vindas. Disponível em: <http://softwarelivre.org/>. Acesso: 27 Mai 2016.

SPINELLI, E.; SANTOS, J. JORNALISMO NA ERA DA PÓS-VERDADE: fact-checking como ferramenta de combate às fake news. Revista Observatório, v. 4, n. 3, p. 759-782, 29 abr. 2018. DOl: https://doi.org/10.20873/uft.24474266.2018v4n3p759.

TOBÍAS, M. A. ; DUARTE, M. C.; KEMCZINSKI, A. Un repositorio digital de contenido fílmico como recurso didáctico [A Digital Repository of Filmic Content as a Teaching Resource]. Comunicar. 2015, 44, 63-71. Disponível em: https://doi.org/10.3916/C44-2015-07. Acesso: 17 Fev. 2017

UNESCO. Sociedade de conhecimento versus economia de conhecimento: conhecimento, poder e política. - Brasília: UNESCO, SESI, 2005. 212 p. Disponível em: <http://unesdoc.unesco.org/images/0014/001417/141702POR.pdf> Acesso: 22 jan. 2016.

WING, J. M. Computational Thinking. Communications of the ACM. March, 2006, Vol. 49, n. 13. 